\title{
Quality service in banking: a longitudinal approach
}

\author{
Lucio Masserini · Caterina Liberati · Paolo \\ Mariani
}

Received: date / Accepted: date

\begin{abstract}
Association between Service Quality and Customers Satisfaction is one of the fundamental relationships in marketing research. Although cross-section analysis has been commonly applied in such a contest, a shift to a dynamic approach appears to be a worthwhile change. A broad range of statistical methods exists for managing data arising from longitudinal designs. Based on pseudo-panel data collected in banking sector, a Latent Growth Curve Model is proposed for analyzing Service Quality in order to capture both intra-individual and inter-individual change in Customer Satisfaction over time. Results also show the impact of reliability on overall satisfaction for different customers' profiles.
\end{abstract}

Keywords Quality Service · Latent Growth Models · Latent Variables · Longitudinal Analysis · Banking Services

\section{Introduction}

Delivering quality service is considered an essential strategy for success and survival in market's competitive environment (Dawkins and Reichheld, 1990; Parasuraman et al, 1985; Reichheld and W. Earl Sasser, 1990; Zeithaml et al, 1990). Relationship among service quality, Customers Satisfaction (CS) and firm profitability, that is one

Lucio Masserini

Statistical Observatory, University of Pisa, Pisa, Italy

E-mail: 1.masserini@adm.unipi.it

Caterina Liberati

Department of Economics Management and Statistics (DEMS), University of Milano-Bicocca, Milan, Italy

E-mail: caterina.liberati@unimib.it

Paolo Mariani

Department of Economics Management and Statistics (DEMS), University of Milano-Bicocca, Milan, Italy

E-mail: paolo.mariani@unimib.it 
of the fundamental associations of the marketing theory (Anderson et al, 1994; Fornell et al, 1996; Zeithaml, 2000), is valid also for the banking services case. Specifically, there has been a convergence of opinion: favorable service quality perceptions lead to improved satisfaction, which is affected by five dimensions (reliability, tangibles, responsiveness, assurance, and empathy). Adapting such framework to the banking industry, we have to underline some differences. The peculiarity of the sector compels one to reflect upon an important thing: differently from industrial or service sectors, banks have a relationship with the clients strictly based on trust (Johnston, 1995), and this means that any management strategy finalized to meet customer desiderata must give priority to this aspect. Over time, some contributions have investigated the link between satisfaction and "reliability" (Levesque and McDougall, 1996; Johnston, 1997; Jamal and Naser, 2002, 2003). In particular, Johnston (1995) revealed that the main sources of dissatisfaction of bank customers are related to integrity and reliability. Based on the traditional operationalization of service quality (Parasuraman et al, 1985, 1988), Levesque and McDougall (1996) distinguished between two main dimensions affecting Customer Satisfaction: the quality of the core service provided by the bank and the quality of the relationship with the bank. Relevant drivers within the first dimension include also "reliability" component whereas relationship drivers count among the others "assurance", and "trust" (Ndubisi, 2006; Manrai and Manrai, 2007). Following such evidences, we investigate the value of the reliability dimension to trigger satisfaction and dissatisfaction in an Italian retail bank. Our paper also models dynamically customers' perceptions in order to provide useful insights about service performance. A shift from a static to dynamic approach appears to be a worthwhile change in study Customer Satisfaction, also emphasized in the marketing literature (LaBarbera and Mazursky, 1983; Bolton and Drew, 1991; Bolton and Lemon, 1999; Cronin et al, 2000). The dearth of panel studies appears to be largely a consequence of high costs and difficulties in obtaining longitudinal data sets and/or maintaining the sample over time (Bove and Johnson, 1999), as well as to the shortness of the product/service lifetime that has to be renewed after some years on the market.

In our work, we analyzed repeated cross-sectional data, due to the impossibility to collect a panel data. We know that such research design presents some limitations. On the other hand, repeated cross-sections suffer much less from typical panel data problems like attrition and nonresponse, and their matching allows to monitor gross change utilizing a time series of cross-sectional data (Frethey-Bentham, 2011). In a seminal paper, Deaton (1985) introduced the use of cohorts to estimate a fixed effects model from repeated cross-sections. In his approach, individuals sharing some common characteristics (most notably, year of birth) were grouped into cohorts, after which the averages within these cohorts were treated as observations in a pseudopanel. In this way, the average behavior of these groups is then tracked over time as long as the sample is continually representative of a population that has a fixed composition (Moffitt, 1993; Collado, 1997; Verbeek, 2008). According to that, we matched the data via a post-hoc segmentation to obtain individual types present over the observational time span.

A broad range of statistical methods exists for analyzing data arising from longitudinal designs. In recent years, Growth Curve Modeling (GCM) has become popular 
and represents one of the most important analytic approaches in the behavioral and social sciences for the study of individual change. In this paper, we propose a Latent Growth Curve Model (LGCM) for analyzing CS, focusing our attention on the peculiar aspects of CS but also on the evolution of the customers' behavior. LGCM is a statistical technique used in the Structural Equation Modeling (SEM) framework for estimating individual growth trajectories observed over a period of time and it is particularly suitable in fixed occasions designs, where measurements are recorded for all individuals at the same set of times, usually regularly spaced. One of the purposes of LGCM is to relate growth parameters to individual characteristics, background and environmental factors, in order to detect systematic inter-individual differences in the individual growth curves. Moreover, its flexibility allows to model growth trajectories by evaluating either a well-known functional form (e.g., linear, quadratic, exponential) or any curvilinear trajectory by freeing one or more of the loadings in the latent curve model (McArdle, 1986). We found a coherent solution and the results illustrated on a real case of study showing the potentiality of our proposal.

The paper is organized as follows. Section 2 describes data and research design. Section 3 illustrates LGCMs. Section 4 presents results and finally section 5 proposes some concluding remarks.

\section{Data and Research Design}

Data used in this study were collected by a large Italian bank, with the aim of monitoring trend in CS over a three years period, after a reduction in the market share, specifically due to some customer segments. The target population consisted of the retail customers who had at least five operational requests to one of the contact points of the bank (call center, e-banking, bank office, and so on) within a year. A simple random sample of customers was selected from the target population for each of the three surveys carried out $(26,969$ at T1, 26681 at T2 and 27744 at T3), but no information about the personal identity of respondents was recorded after each wave. Hence, the research design is composed by three regularly time spaced (T1, T2 and T3) cross-sectional surveys. At each occasion, customers were interviewed on the same questionnaire by using a CATI (Computer Assisted Telephone Interviewing) system. The questionnaire was framed according to the system of measurement of service quality SERVQUAL Parasuraman et al $(1985,1988)$, which is characterized by a set of items under five dimensions (reliability, tangibles, responsiveness, assurance, and empathy $)^{1}$. Overall satisfaction with the service provided by the bank was evaluated by introducing a specific question, whose responses represent the outcome variable under study. For each specific item, as well as for the overall satisfaction, respondents could express their assessment on a ten points Likert scale. Finally, sociodemographic characteristics were also collected, in order to profile respondents. Preliminary descriptive statistics show a constant trend over time for the mean score obtained for each specific dimension evaluated, as well as for the overall satisfaction (Table 1).

\footnotetext{
1 Such framework allowed to use the reliability as a proxy of customers trust for the bank.
} 
Table 1 Means of scores and standard deviations of SERVQUAL dimensions per wave.

\begin{tabular}{lcccccc}
\hline & \multicolumn{2}{c}{ T1 } & \multicolumn{2}{c}{ T2 } & \multicolumn{2}{c}{ T3 } \\
& Mean & Std Dev & Mean & Std Dev & Mean & Std Dev \\
\hline Tangible aspects & 8.71 & 1.288 & 8.74 & 1.304 & 8.76 & 1.296 \\
Reliability & 9.50 & 0.824 & 9.48 & 0.853 & 9.42 & 0.871 \\
Ability to answer & 9.43 & 0.871 & 9.41 & 0.893 & 9.36 & 0.898 \\
Capacity of reassurance & 9.40 & 0.888 & 9.40 & 0.925 & 9.32 & 0.933 \\
Empathy & 9.18 & 0.986 & 9.22 & 0.995 & 9.20 & 0.971 \\
Overall satisfaction & 7.47 & 1.305 & 7.59 & 1.303 & 7.52 & 1.279 \\
\hline
\end{tabular}

Moreover, the distribution of respondents per wave is fairly homogeneous according to the main socio-demographic characteristics, namely for age, gender, education and employment position, respectively. Specifically, the main features of the sample show that more than $60 \%$ of respondents are aged between 26 and 59 years old, are equally distributed for gender, have a prevalence of low and medium educational qualification, and a distribution of employment position that seems to be representative of the different professional segments (Table 2).

Table 2 Percentage distributions of socio-demographics characteristics across the three waves

\begin{tabular}{|c|c|c|c|}
\hline Age classes & T1 & T2 & T3 \\
\hline Less than 25 yrs & 7.8 & 7.3 & 8.4 \\
\hline $25-35$ yrs & 18.2 & 18.0 & 18.8 \\
\hline $36-46$ yrs & 25.6 & 25.4 & 24.9 \\
\hline $47-59$ yrs & 24.8 & 24.3 & 24.3 \\
\hline More than 59 yrs & 23.6 & 25.0 & 23.5 \\
\hline \multicolumn{4}{|l|}{ Gender } \\
\hline Male & 47.1 & 46.3 & 48.7 \\
\hline Female & 52.9 & 53.7 & 51.3 \\
\hline \multicolumn{4}{|l|}{ Education } \\
\hline University Degree & 11.9 & 12.4 & 13.3 \\
\hline High school & 46.7 & 46.3 & 47.5 \\
\hline Middle school & 28.5 & 28.5 & 27.7 \\
\hline Primaty school & 12.1 & 12.2 & 11.0 \\
\hline No title & 0.6 & 0.6 & 0.5 \\
\hline \multicolumn{4}{|l|}{ Employment position } \\
\hline Enterpreneur/Professional & 10.0 & 10.7 & 10.1 \\
\hline Executive & 1.5 & 1.5 & 1.5 \\
\hline Employee & 24.7 & 24.8 & 26.9 \\
\hline Workman & 7.7 & 8.1 & 7.7 \\
\hline Farmer/Trader & 8.6 & 8.0 & 6.4 \\
\hline Retired & 22.3 & 24.1 & 22.1 \\
\hline Housewife & 13.5 & 12.8 & 12.2 \\
\hline Student & 4.4 & 4.1 & 5.0 \\
\hline Not available & 7.3 & 6.0 & 8.0 \\
\hline
\end{tabular}

Due to privacy concerns, only an encryption key id for each of the client present in the sample in every wave was provided, therefore, it was possible to analyze the overall data but it was not possible to obtain longitudinal information on individual cus- 
tomers interviewed (as in panel data). Naturally, such picture, which is very common in marketing research, allowed to obtain 3 sub-samples with slight variations in terms of size and changes of profile clients as marital status, level of education, profession due to turn-over. In order to overcome this limit we generated Super Customers (SC) using an a priori segmentation based on employment status, educational qualification, gender and age. Our procedure was inspired by Wedel and Kamakura (1998), which proposed a post-hoc segmentation by reducing the number of entities being dealt with into a manageable number of groups that are mutually exclusive and share well defined characteristics. The identification of this new subject was provided using as profile all possible combinations of the considered variables. Each customer, into each wave, is linked to a unique profile. For example "graduated, manager, male, 50 years old" represent one of this profiles. After this, all respondents with the same characteristics were collapsed into the new customer (SC) (Verbeek and Nijman, 1992), and averaging all values of the original characteristics. This transformation implied a loss of some information, for example the number of customer that compose the SC and a reduction in terms of variance because we consider only the average. We keep only the profiles that are present into all waves and we procede at the generation of a new database where longitudinal monitoring was possible. The total number of Super Customers (patterns of individuals) obtained was equal to 1570 over the three waves, lower than the one obtained by all of the possible combinations of the features used for the composition. This number results by considering the set of Super Customers common to the three panel waves, as shown in Figure 1.

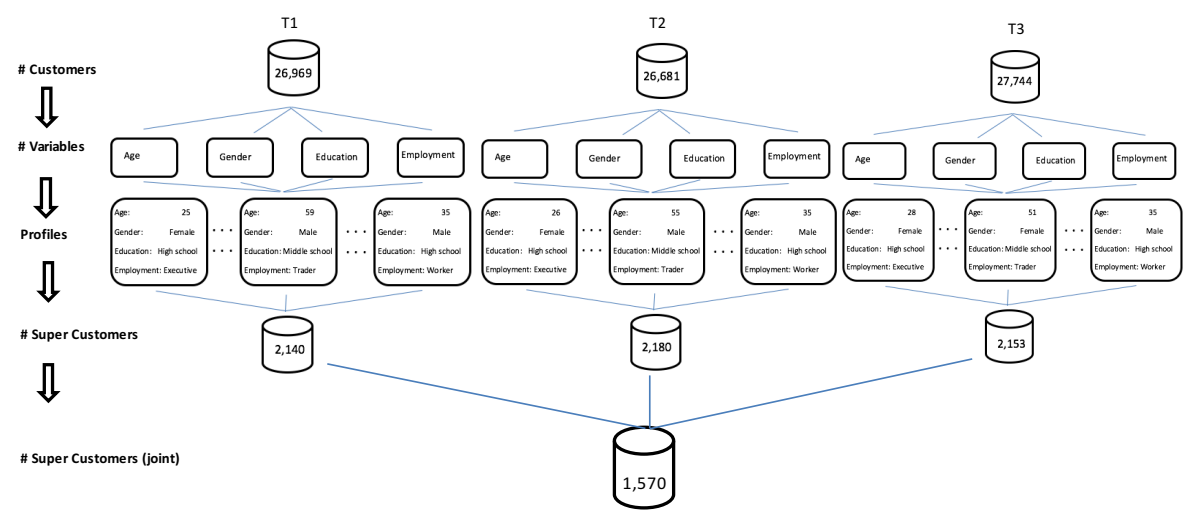

Fig. 1 Flow chart of data matching 


\section{Latent Growth Curve Models}

\subsection{Modeling growth}

During the last thirty years, Growth Curve Modeling (GCM) has become popular in the analysis of longitudinal and panel data (McArdle, 1986; Meredith and Tisak, 1990; Singer and Willett, 2003) for the study of individual change. More specially, GCM is a statistical technique that is able to capture both intra-individual and interindividual change over time, by assuming individual growth patterns as represented by curves of the same functional form and randomly varying parameters for describing differences in growth trajectories across individuals. The analysis of longitudinal and panel data through GCM can be approached from several perspectives. Latent Growth Curve Models (LGCM), under the Structural Equation Modeling (SEM) framework, adopts a latent variable view and assumes the existence of continuous underlying or latent trajectories for each individual. Hence, unobserved growth trajectories are observed indirectly through a set of repeated measures (Bollen, 2002), treated as imperfect indicators of the underlying trend (Curran and Bollen, 2001), and individual differences both in the initial status and in the growth rate are included in the model as latent variables (Muthén and Khoo, 1998). Latent variable means for the intercept and slope factors describe the mean growth, whereas inter-individual differences in the parameters describing the growth curve are modeled as the (co)variances of the intercept and slope factors. Several advantages are associated with the use of LGCM approach under the SEM framework over competing methods (e.g., Multilevel Modeling or Generalized Estimating Equations): among others, the possibility of testing hypotheses about specific trajectories; the introduction of flexible growth functional forms; the incorporation of both time-varying and time-invariant covariates; and all the typical advantages of SEMs, such as the ability to evaluate the adequacy of models using model fit indices, the ability to account both for measurement error by using latent repeated measures and the possibility to deal effectively with missing data (Enders, 2001).

\subsection{Latent Growth Curve approach}

The LGCM can be expressed in terms of a measurement model and a structural model, under the SEM framework. Given a set of repeated measures of an outcome variable $y$, observed for individual $i=1, \ldots, n$ at occasion $t=1, \ldots, T$, the measurement model defines the trajectory equation and is formulated as a confirmatory (or restricted) common factor model, where the latent factors represent the latent curve components, as follows in matrix notation (Bollen and Curran, 2006):

$$
\mathbf{y}_{i t}=\boldsymbol{\Lambda} \boldsymbol{\eta}_{i}+\boldsymbol{K} \mathbf{w}_{i}+\boldsymbol{\varepsilon}_{i}
$$

Here, $\mathbf{y}_{i t}$ is a $T \times 1$ vector containing $T$ repeated measures of an outcome variable $\mathbf{y}$ for individual $\mathrm{i}, \boldsymbol{\eta}_{i}$ is an $m \times 1$ vector of underlying latent factors, also known as growth factors (i.e., initial status and growth trend factors); $\Lambda$ is a $T \times m$ matrix of factor loadings for $T$ time points, which relates the observed repeated measures to 
the underlying latent factors; $\mathbf{w}_{i}$ is a $T \times 1$ vector of time-varying covariates (TVCs), whose values change across time and can help to explain or predict the variation in the outcomes beyond time; $\boldsymbol{K}$ is a $T \times T$ matrix of regression coefficients of the repeated measures on the TVCs (assuming $T$ observations for both $\mathbf{y}$ and $\mathbf{w}$ ); and $\boldsymbol{\varepsilon}_{i}$ is $T \times 1$ random vector of time-specific residuals, independent between individuals and times of waves, whose elements are assumed with zero-mean and multivariate normal. In equation (1), the observed repeated measures are related to the underlying latent factors through the factor loadings matrix and elements are fixed to specific values to characterize hypothesized trajectories. Each column of this matrix represents a specific aspect of change (intercept and slope) and can be defined either by a well-known functional form specified a priori (e.g., linear, quadratic, exponential) or by an unspecified trajectory, obtained by freeing one or more loadings in the latent curve model (McArdle, 1988; Meredith and Tisak, 1990), whose values are estimated from the data. Models with freely estimated factor loadings give great flexibility in fitting nonlinear forms between two any time points, thus resulting in a closer curve to the empirical data.

The structural model is used to express the vector of underlying latent factors contained in $\boldsymbol{\eta}$ in terms of a mean and individual deviations from the mean. To explain individual variation in the latent growth factors, one or more time-invariant covariates (TICs) can also be included, whose values vary across individuals but are constant over time. Hence, the conditional structural model for the latent curve parameters can be defined as follows:

$$
\boldsymbol{\eta}_{i}=\boldsymbol{\mu}_{\eta}+\Gamma \mathbf{x}_{i}+\boldsymbol{\zeta}_{i}
$$

where $\boldsymbol{\mu}_{\eta}$ is an $m \times 1$ vector of factor means, $\mathbf{x}_{i}$ is a $k \times 1$ vector of time-invariant covariates for the latent variables; $\Gamma$ is $m \times k$ matrix of regression coefficients between the latent factors and the observed covariates; and $\zeta$ is an $m \times 1$ vector of residuals, which represent the random components capturing individual variations in growth factors means over time, whose elements are assumed to have a multivariate normal distribution with zero mean. Moreover, two further matrices are defined: $\boldsymbol{\Psi}$, an $m \times m$ symmetric covariance matrix of the equation errors term $\zeta_{i}$, among the latent trajectory factors, whose elements represent the variances and covariances of the latent curve random coefficients; and $\Theta_{\varepsilon}$, a $T \times T$ symmetric covariance matrix of residuals, $\boldsymbol{\varepsilon}_{i}$. Specifically, often an equality constraint is placed on the diagonal elements of $\boldsymbol{\Theta}_{\varepsilon}$, and off-diagonal values are fixed at zero. However, among the benefits of fitting growth curves in the SEM framework is also the ability to test and evaluate a variety of different residual structures (Grimm and Ram, 2011).

Given its desirable asymptotic properties, Maximum likelihood (ML) is the most popular method for the estimation of the model parameters of LGCM under the SEM approach. However, in order to take into account for missing values, Full Information Maximum Likelihood (FIML), also known as direct ML (Arbuckle, 1996) can be employed. FIML utilizes all the information of the observed data and maximizes the likelihood of the model given the observed data, since the likelihood function is computed for each case by using only those variables that are available for that case. In cases of missing completely at random (MCAR) or missing at random (MAR), 
FIML is more efficient and less biased than the traditional approaches (e.g., listwise deletion, pairwise deletion, or mean imputation methods) (see, for more details Little and Rubin (2002))

\section{Results}

The analysis was performed by using the software Mplus 5.21 (Muthén and Muthén, 1998-2012), and parameters were estimated with the Full Information Maximum Likelihood (FIML) method, with standard errors and a chi-square test statistic that are robust to non-normality of data (Yuan and Bentler, 2000). Given the relatively large sample size, FIML is expected to produce asymptotically efficient and consistent estimates. The model fit was evaluated by using goodness-of-fit statistics and fit indices (Hu and Bentler, 1999) and showed a satisfactory overall fit, with low average residuals and very good values of the incremental fit indices (Chi-square $=206.154$; $\mathrm{df}=16 ; \mathrm{P}<0.001 ; \mathrm{CLI}=0.989 ; \mathrm{TFI}=0.970 ; \mathrm{RMSEA}=0.018 ; \mathrm{SMR}=0.016$ ).

\subsection{Model specification}

The outcome variable under study $y_{i t}$ is given by the overall customer satisfaction with the service provided by the bank and is denoted with $S A T_{i t}$. Since it is observed at three equally spaced time points $(T=3)$, the corresponding repeated measurements are indicated with $S A T 1, S A T 2$ and $S A T 3$, where the index identifying customers is omitted to simplify notation. Data are modeled by considering two latent variables $(m$ $=2$ ): the intercept factor $\eta_{1 i}$, which represents the initial level of overall satisfaction; and the slope factor $\eta_{2 i}$, which determines the rate of change over the time period.

To predict growth in overall satisfaction over time, a random coefficients model with a freely estimated factor loading at $\mathrm{T} 2$ was estimated. To attempt to explain inter-individual variability in intra-individual change, time-invariant covariates were included for representing different customers' profiles.

More specifically, a freely estimated factor loading allows for a more flexible estimation of the growth trajectories over time and gives the possibility of capturing any nonlinear change patterns. For this model, the matrix $\Lambda$ of factor loadings is $3 \times 2$, in which the elements in the first column $\left(\lambda_{t 1}\right)$ define the intercept while those of second are the shape factors for the slope $\left(\lambda_{t 2}\right)$. In particular, loadings for the intercept factor are set equal to 1 for all time points $\left(\lambda_{t 1}=1,1,1\right)$ to represent the influence of a constant on the repeated measures; instead, regarding the column of shape factors, the first and last loadings are respectively fixed at 0 and 1 for identification purposes, while the loading at T2 is estimated from the data $\left(\lambda_{t 2}=0, \lambda_{T 2}, 1\right)$.

Time-invariant categorical predictors of random intercept and slope were collected in vector $\mathbf{x}_{i}$ and included in the model as dummy variables after defining a reference category for each covariate. In particular, the considered predictors were: Employment position (with categories entrepreneur and professional, executive, employee, farmer/trader, workman, student, housewife, retired; reference is employee), Education (university degree, high school, middle school, primary school, no title; 
reference is high school), Age groups (less than 25 yrs, 25-35 yrs, 36-46 yrs; 47-59 yrs, more than 59 yrs; reference is $36-46$ yrs) and Gender (male, female; reference is female). Hence, a binary variable was created for the categories of each explanatory variable, with the exception of the reference category. Therefore, the mean intercept and slope will correspond to the average of the initial level and rate of change in overall satisfaction, respectively, and will represent a hypothetical customer having the following characteristics: $36-46$ years old, female, with high school education and with a job as an employee.

Finally, the time-varying covariate Reliability was introduced to account for the banks ability to perform the promised service dependably and accurately. Given that it is on the same scale of the dependent variable and varies across individuals and time, it can remove occasion-specific variance and help to better predicting the outcome measures at the corresponding time points. Its values are summarized in vector $\mathbf{w}_{i t}$ and can be expressed as RELT1, RELT2 and RELT3.

The estimated model can be represented by the following three equations:

$$
\begin{aligned}
& S A T_{i t}=\eta_{1 i}+\lambda_{t} \eta_{2 i}+\sum_{t} k_{t} \mathbf{w}_{i t}+\varepsilon_{i t} \\
& \eta_{1 i}=\mu_{1}+\gamma_{1} \mathbf{x}_{i}+\zeta_{1 i} \\
& \eta_{2 i}=\mu_{2}+\gamma_{2} \mathbf{x}_{i}+\zeta_{2 i}
\end{aligned}
$$

Eq. 3 defines individual growth trajectories whereas Eqs. $4-5$ specify the intercept and slope factors in function of the vector of time-invariant covariates.

\subsection{Latent growth model}

Parameter estimates for the latent growth model with a freely estimated factor loading at T2 and two latent growth factors (intercept and slope) are summarized in Table 3 and Figure 2. In Table 3, $\mu_{1}$ and $\mu_{2}$ are the parameters indicating the mean intercept and mean slope across all cases, respectively; $\Psi_{11}$ and $\Psi_{22}$ are the corresponding variances, which represent individuals deviations from the means; and $\Psi_{12}$ is the covariance between intercept and slopes. From this table it is possible to obtain the mean level of overall satisfaction at T1 for the reference profile $\left(\mu_{1}=5.684\right.$; $\mathrm{P}<$ $0.001)$ and the mean slope $\left(\mu_{2}=0.352 ; \mathrm{P}<0.001\right)$, with the latter showing a general but slight increase in overall satisfaction over time.

The introduction of a freely estimated factor loading at $\mathrm{T} 2$ allows to capture the nonlinear form of the individual latent trajectories. In particular, the estimated loading reflects the proportion of change between the first two time points relative to the total change occurring from the initial and the final time point. Because its value is significant and greater than $1(1.035 ; \mathrm{p}<0.001)$, the trajectory has a small peak at $\mathrm{T} 2$ within the overall growth interval. Furthermore, the significant residual variance of the intercept $\left(\Psi_{11}=0.123 ; \mathrm{P}<0.001\right)$ and for the slope growth factors $\left(\Psi_{22}=0.121\right.$; $\mathrm{P}<0.001)$ indicate a substantial variation in the overall satisfaction at $\mathrm{T} 1$ and in the rate of change, even after taking into account the observed time-invariant covariates. Finally, a significant negative covariance between initial overall satisfaction and rate 
Table 3 Parameter estimates of the latent growth curve model

\begin{tabular}{lccc}
\hline Parameter & Estimate & Standard error & p-value \\
\hline $\begin{array}{l}\text { Growth factor means } \\
\text { intercept }\left(\mu_{1}\right)\end{array}$ & 5.684 & 0.171 & 0.000 \\
slope $\left(\mu_{2}\right)$ & 0.352 & 0.147 & 0.017 \\
\hline $\begin{array}{l}\text { Growth factor variances } \\
\text { intercept }\left(\Psi_{11}\right)\end{array}$ & 0.123 & 0.003 & 0.000 \\
slope $\left(\Psi_{22}\right)$ & 0.121 & 0.004 & 0.000 \\
\hline $\begin{array}{l}\text { Growth factor covariances } \\
\text { intercept vs slope }\left(\Psi_{12}\right)\end{array}$ & -0.114 & 0.003 & 0.000 \\
\hline $\begin{array}{l}\text { Shape factor } \\
\lambda_{T 2}\end{array}$ & 1.035 & 0.016 & 0.000 \\
\hline
\end{tabular}

of change $\left(\Psi_{12}=-0.114 ; \mathrm{P}<0.001\right)$ is also observed, with a correlation corresponding to -0.930 . This result reveals that, on average, customers more satisfied at $\mathrm{T} 1$ have a lower or even a negative growth rate in satisfaction than less satisfied customers. Usually, this is a typical tendency that happens if marketers raise expectations too high, the buyer is likely to be disappointed (Kotler and Keller, 2000).

\subsection{Predicting latent growth factors}

Figure 2 shows a path diagram of the estimated latent growth model with the two latent factors $\left(\eta_{1}\right.$ and $\left.\eta_{2}\right)$. The path diagram gives a pictorial representation of the equations of the latent curve model for the three repeated outcome measures of overall satisfaction (SAT1, SAT2 and SAT3). Here, rectangular boxes represent observed variables (repeated outcome variables and time-invariant and time-varying covariates) whereas latent variables are enclosed in circles. One-headed arrows represent directional relationships, such as regression coefficients and factor loadings, whereas two-headed arrows represent covariances. The estimated regression coefficients for the dummy time-invariant covariates on the latent growth factors are grouped in boxes for each variable (Employment position, Education and Demographic characteristics: Age and Gender) and enclosed in parentheses next to the corresponding variable label. Here, the first coefficient refers to the effects on the intercept whereas the second to the slope, respectively; furthermore, asterisks throughout the figure indicate parameters significantly different from zero at level $\mathrm{p}<0.05(*), \mathrm{p}<0.01\left(^{* *}\right)$ and $\mathrm{p}$ $<0.001$ (***) $^{*}$.

To predict inter-individual variability in latent growth factors over time, the effect of time-invariant covariates were evaluated. In this respect, significant differences $(\mathrm{p}<0.001)$ in baseline customer satisfaction are observed for Employment position, Education, Demographic characteristics (Age groups and Gender). More specifically, about Employment position, the baseline level of satisfaction is significantly higher for workmen $(+0.115)$, retirees $(+0.153)$ and housewives $(+0.124)$ but lower for entrepreneurs/professionals (-0.148), executives (-0.090) and, above all, for students 


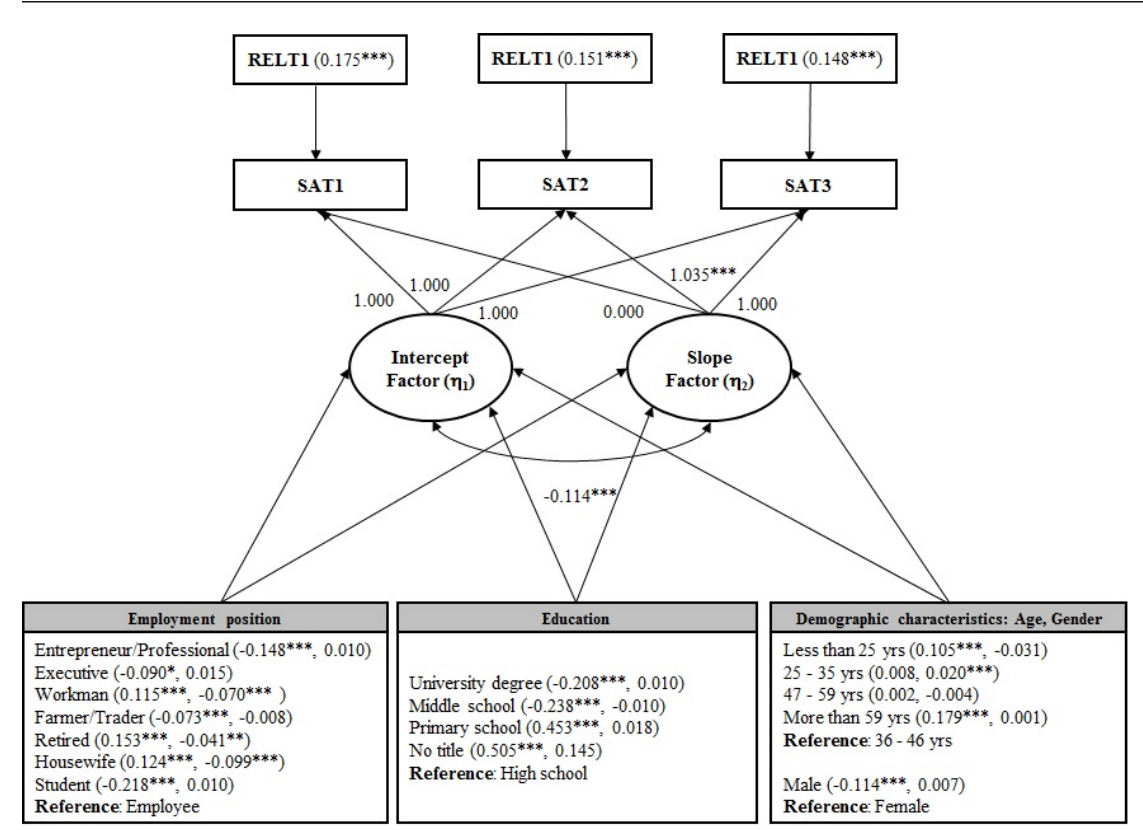

Fig. 2 Path diagram of the LGCM with time-varying and time-invariant covariates

(-0.218), compared to the employees chosen as the reference category. Accordingly, the results indicate that people employed in highly skilled jobs and students seem to be, on average, less satisfied, probably also due to the different kind of services they request or utilize. About Education, the baseline level of satisfaction is significantly higher for people with low or very low qualification, compared to High school chosen as the reference category: middle school $(+0.238)$, primary school $(+0.453)$ and no title $(+0.505)$. On the other hand, low and medium educational levels are associated with a higher level of satisfaction: middle school $(+0.238)$, primary school $(+0.453)$ and no title $(+0.505)$ but lower for university degree $(-0.208)$. Moreover, the baseline satisfaction is significantly higher for customers with age less than 25 yrs $(+0.105)$ and, above all, for customers with more than 59 yrs $(+0.179)$ while no difference is observed for the other classes. Finally, males (-0.141) show a lower level of satisfaction compared to females.

As regard the random slopes, only a few parameters are significantly different from zero, and this means that although the initial level of satisfaction is different due to the individual characteristics, growth rates are more homogeneous. In particular, growth trajectories are lower than average only for some Employment positions: workmen (-0.070), retirees (-0.041) and housewives (-0.099). Finally, about Age groups, 25-35 yrs old have slightly higher growth rate than 36-46 yrs chosen as the reference category.

The model results also show that the time-varying covariate Reliability has a significant and positive effect on overall satisfaction at all time points (T1, T2, T3). In 
particular, the effect seems to be rather constant during the three waves, although with a weak tendency to decrease over time.

The trajectories estimated from the model were represented graphically in Figure 3 for the considered sub-groups of customers (Employment position, Education, Age groups and Gender). Based on the model predictions, the figure shows an increase in overall satisfaction between $\mathrm{T} 1$ and $\mathrm{T} 2$ but a relative stability in the successive period. Specifically, individual variation in the initial level of satisfaction is higher for Education than for Employment position. Instead, as regard the growth rate, individual differences are less evident, as shown by the corresponding trajectories.
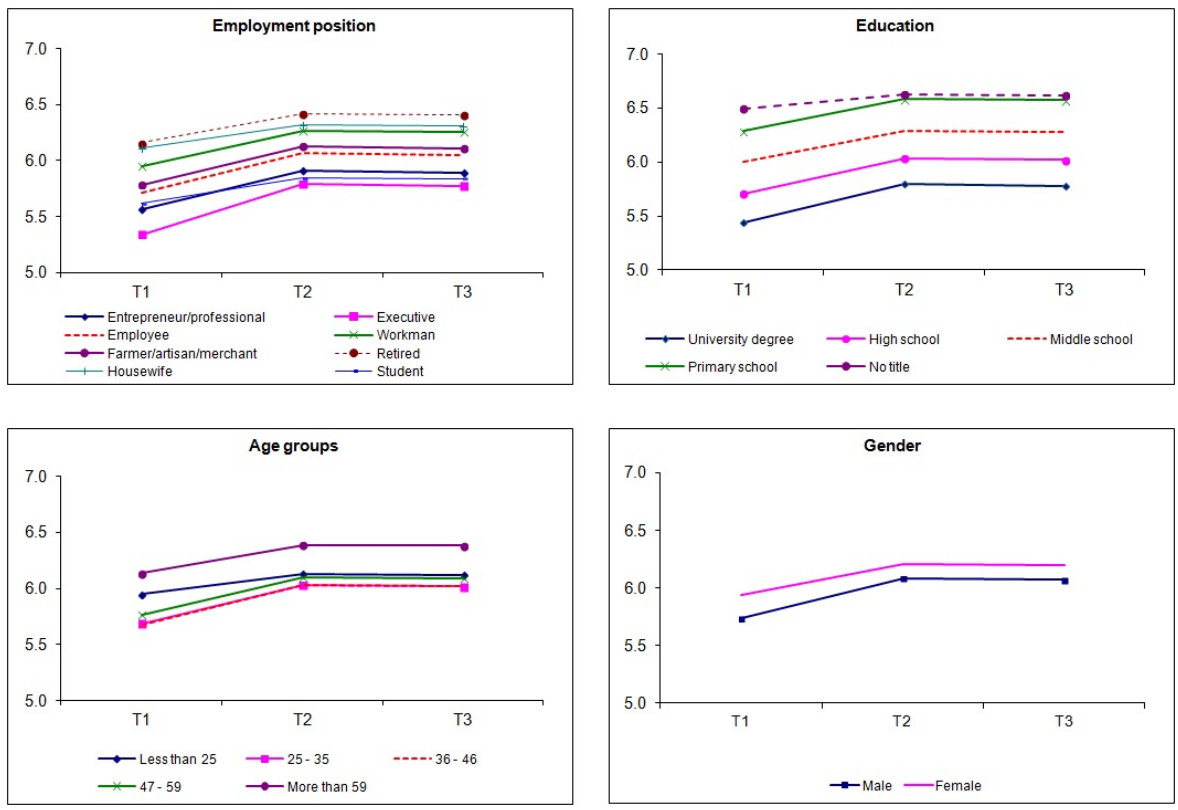

Fig. 3 Estimated trajectories from the LGCM with time-varying and time-invariant covariates

\section{Conclusions}

Quality service is a strategy for success and survival in business market's competitive environment, as well as for banks. As it has been shown in several contributions, modeling SERVQUAL dimensions aids to understand satisfaction, although such framework presents some peculiarities in case of financial services. Specifically, in this sector it is interesting to investigate the link between overall satisfaction and reliability, since banks have a relationship with their own clients strictly based on trust. In our paper, we studied the reliability dimension as a satisfaction ignition, using a Latent Growth Curve Model. Our proposed strategy takes into account two relevant aspects: the first related to the methodology employed in the analysis, the 
second related to the empirical practices of data collection. The selection of LCGMs has been carried out based on their capability of fitting any nonlinear or unspecified trajectories giving considerable flexibility to the estimation process. Such feature is useful whenever the functional form of the individual growth trajectories cannot be specified by a known function and the number of time period is rather limited (usually not exceeded three or four periods) just as in our dataset. For what concerns data collection, it has to be pointed out that it is uncommon to face with panel data in real business applications: this is due to the frequent market's changes that influence product life and typologies of consumers. Although pseudo-panels show some drawbacks, they are often the unique longitudinal source available. In our study, individuals sharing gender, age class, education and employment position, are grouped into cohorts, and treated as observations of a longitudinal phenomenon (as in pseudopanel setting). The results show different reactions of the compared profiles to some medium-term actions operated by the management: such tendency highlight also a change in customer needs that can influence bank performance in the long run. In particular, a substantial homogeneity of path is observed for any job position, except for the entrepreneur/professionals that have better perception of the service. Also age does not discriminate among different behaviors especially if we consider extreme classes; gender, instead, uncovers that female customers are more satisfied than the males.

\section{References}

Anderson E, Fornell C, Lehmann D (1994) Customer satisfaction market share, and profitability: Findings from sweden. Journal of Marketing 58:53-66

Arbuckle JL (1996) Full information estimation in the presence of incomplete data. In: Marcoulides GA, (Eds) RES (eds) Advanced structural equation modeling, Mahwah, New Jersey: Lawrence Erlbaum Associates

Bollen K (2002) Latent variables in psychology and the social sciences. Annu Rev Psychol 53:605-34

Bollen KA, Curran PJ (2006) Latent Curve Models. Wiley, New York

Bolton RN, Drew JH (1991) A longitudinal analysis of the impact of service changes on customer attitudes. Journal of Marketing 55(1):1-10

Bolton RN, Lemon K (1999) A dynamic model of customers' usage of services: Usage as an antecedent and consequence of satisfaction. Journal of Marketing Research 36:171-186

Bove LL, Johnson L (1999) Does "true" personal or service loyalty last? a longitudinal study. Journal of Services Marketing 23:187?194

Collado M (1997) Estimating dynamic models from time series of independent crosssections. Journal of Econometrics 82:37-62

Cronin J, Brady M, Hult G (2000) Assessing the effects of quality, value, and customer satisfaction on consumer behavioral intentions in service environments. Journal of Retailing 76(2):193-218 
Curran P, Bollen K (2001) The best of bothworlds: combining autoregressive and latent curve models. In: Collins LM, (Eds) AGS (eds) New Methods for the Analysis of Change, Washington, DC: American Psychological Association, pp 105-136

Dawkins P, Reichheld E (1990) Customer retention as a competitive weapon. Directors and Boards 14:42-47

Deaton A (1985) Panel data from time series of cross-sections. Journal of Econometrics 30:109-126

Enders C (2001) A primer on maximum likelihood algorithms available for use with missing data. Structural Equation Modeling 8(1):128-141

Fornell C, Johnston MD, Anderson E, Cha J, Bryant BE (1996) The american customer satisfaction index: Nature, purpose, and findings. Journal of Marketing 60:718

Frethey-Bentham C (2011) Pseudo panels as an alternative study design. Australasian Marketing Journal 19:281-292

Grimm KJ, Ram N (2011) Growth curve modeling from an sem perspective. In: T Little NCE B Laursen (ed) Handbook of developmental research methods, New York: Guilford Publications, pp 411-431

Hu L, Bentler PM (1999) Cutoff criteria for fit indexes in covariance structure analysis: Conventional criteria versus new alternatives. Structural Equation Modeling: A Multidisciplinary Journal 6(1):1-55

Jamal A, Naser K (2002) Customer satisfaction and retail banking: an assessment of some of the key antecedents of customer satisfaction in retail banking. International Journal of Bank Marketing 20(4):146-160

Jamal A, Naser K (2003) Factors influencing customer satisfaction in the retail banking sector in pakistan. International Journal of Commerce and Management 13(2):29-53

Johnston R (1995) The determinants of service quality: satisfiers and dissatisfiers. International Journal of Service Industry Management 6:53-71

Johnston R (1997) Identifying the critical determinants of service quality in retail banking: importance and effect. International Journal of Bank Marketing 15(4):111-116

Kotler P, Keller K (2000) Marketing Management. New Jersey: Pearson Education.

LaBarbera P, Mazursky D (1983) A longitudinal assessment of consumer satisfaction/dissatisfaction: The dynamic aspect of the cognitive process. Journal of Marketing Research 20:393-404

Levesque T, McDougall G (1996) Determinants of customer satisfaction in retail banking. International Journal of Bank Marketing 14(7):12-20

Little J, Rubin DB (2002) Statistical Analysis with Missing Data, 2nd Edition. New York, NY: John Wiley and Sons

Manrai L, Manrai A (2007) A field study of customers' switching behavior for bank services. Journal of Retailing and Consumer Services 14(7):2008-2015

McArdle JJ (1986) Latent variable growth within behavior genetic models. Behavior Genetics 16:163-200

McArdle JJ (1988) Dynamic but sructural equation modeling of repeated measure data. In: Cattel RB, (Eds) JN (eds) Handbook of multivariate experimental psychology (2nd edition), New York, Plenum Press, pp 561-614 
Meredith WM, Tisak J (1990) Latent curve analysis. Psychometrika 55:107-122

Moffitt R (1993) Identification and estimation of dynamic models with a time series of repeated cross-sections. Journal of Econometrics 59:99-123

Muthén B, Khoo ST (1998) Longitudinal studies of achievement growth using latent variable modeling. Learning and Individual Differences, Special issue: latent growth curve analysis 10:73-101

Muthén LK, Muthén BO (1998-2012) Mplus user's guide, sixth edition. los angeles: Muthén and muthén. URL http://statmodel.com/ugexcerpts.shtml.

Ndubisi N (2006) A structural equation modelling of the antecedents of relationship quality in the malaysia banking sector. Journal of Financial Services Marketing 11(2):131-141

Parasuraman A, Zeithaml VA, Berry LL (1985) A conceptual model of service quality and its implications for future research. Journal of Marketing 49(4):41-50

Parasuraman A, Zeithaml VA, Berry LL (1988) Servqual: a multiple-item scale for measuring consumer perceptions of service quality. Journal of Retailing 64(1):1240

Reichheld F, W Earl Sasser J (1990) Zero defections: Quality comes to services. Harvard Business Review 68:105-111

Singer JD, Willett JB (2003) Applied Longitudinal Data Analysis: Modeling Change and Event Occurrence. Oxford University Press, New York

Verbeek M (2008) Pseudo-panels and repeated cross-sections. In: L M, P S (eds) The Econometrics of Panel Data, Advanced Studies in Theoretical and Applied Econometrics, Springer, pp 369-383

Verbeek M, Nijman T (1992) Can cohort data be treated as genuine panel data? Empirical Economics 17(1):9-23

Wedel M, Kamakura W (1998) Market Segmentation: Conceptual and Methodological Foundations. Kluwer Academic Publishers, Dordrecht

Yuan KH, Bentler PM (2000) Three likelihood-based methods for mean and covariance structure analysis with nonnormal missing data. Sociological Methodology 630(1):165-200

Zeithaml VA (2000) Service quality, profitability, and the economic worth of customers: What we know and what we need to learn. Journal of the Academy of Marketing Science 28(1):67-85

Zeithaml VA, Parasuraman A, Berry L (1990) Delivering Quality Service: Balancing Customer Perceptions and Expectations. New York: The Free Press 